\title{
Sequentially induced sputum in patients with asthma or chronic obstructive pulmonary disease
}

\author{
K. Richter, O. Holz, R.A. Jörres, M. Mücke, H. Magnussen
}

Sequentially induced sputum in patients with asthma or chronic obstructive pulmonary disease. K. Richter, O. Holz, R.A. Jörres, M. Mücke, H. Magnussen. (C)ERS Journals Ltd 1999.

ABSTRACT: It has been demonstrated that consecutive samples of induced sputum may differ with respect to cellular composition. The aim of this study was to compare two sequential sputum samples in patients with chronic obstructive pulmonary disease (COPD) and asthma with different severity.

Two sputum inductions were performed $30 \mathrm{~min}$ apart and processed separately in healthy subjects $(n=11)$, patients with moderate to severe COPD $(n=10)$, asthmatics treated with $\beta_{2}$-agonists alone (group $1, n=11$ ), inhaled steroids (group $2, n=12$ ) or systemic steroids (group $3, n=7$ ).

In healthy subjects and asthma group 2, percentages of neutrophils decreased significantly between the two sputum inductions but did not change in COPD and asthma group 3. Percentages of eosinophils did not change significantly in any group of patients. Concentrations of interleukin (IL)-8 decreased significantly in the control group and asthma groups 1 and 2 but not in asthma group 3 and the COPD group.

These data demonstrate differences in sputum composition between two consecutive samples which were most pronounced in healthy subjects. Therefore, pooling of sputum samples may affect the results, particularly in healthy subjects, in contrast to subjects with more severe asthma or chronic obstructive pulmonary disease. These findings may be suggestive of differences in the distribution of inflammation along the airways between distinct airway diseases.

Eur Respir J 1999; 14: 697-701.
Krankenhaus Grosshansdorf, Zentrum für Pneumologie und Thoraxchirurgie, LVA Freie und Hansestadt Hamburg, Grosshansdorf, Germany.

Correspondence: K. Richter, Krankenhaus Grosshansdorf, Zentrum für Pneumologie und Thoraxchirurgie, LVA Freie und Hansestadt Hamburg, D-22927 Grosshansdorf, Federal Republic of Germany. Fax: 494102601862

Keywords: Asthma

chronic obstructive pulmonary disease induced sputum

sequential inductions

Received: November 161998 Accepted after revision April 291999

This study was supported by the Landesversicherungsanstalt (LVA) Freie und Hansestadt Hamburg, Germany.
Within the past few years sputum induction by inhalation of hypertonic saline has been established as an important noninvasive tool to obtain cellular and soluble factors from the airways. The method has been demonstrated to be reproducible, sensitive and valid [1-3] and several technical factors have been examined which could influence the results [4]. If sputum inductions are repeated within 8 or $24 \mathrm{~h}$ considerable increases of neutrophils are found [5, 6]. However, there are few data about changes in sputum composition during repeated sputum inductions within shorter time intervals or even during a single induction procedure. Although induction methods differ with regard to total induction time, it is common to pool the sputum obtained within repetitive inhalations $[3,7]$. Recently, it has been shown that in healthy subjects and subjects with mild asthma the sputum samples obtained during three consecutive $10 \mathrm{~min}$ inhalation periods, with increasing saline concentration, differ with respect to cell differentiation and fluid phase markers [8]. These results suggested that sequential sputum specimens reflect different parts of the tracheobronchial tree. Similar changes of sputum composition during sequential sputum induction have been reported by GERSHMAN et al. [9] in patients with asthma. As a consequence, KIPS et al. [10] recently have emphasized the need for a standardization of induction time.

Based on these observations the authors reasoned whether differences in the cellular composition of sequentially collected sputum samples could depend on the type and the severity of the airway disease. It may be suggested that the decrease in neutrophil numbers in the third versus the first sputum samples disappears in chronic obstructive pulmonary disease (COPD) or more severe asthma, thereby indicating a different inflammatory pattern within the tracheobronchial tree as compared to healthy subjects or patients with mild asthma.

To test this hypothesis two sequentially obtained sputum samples were analysed in normal subjects, patients with COPD, and three groups of asthmatic patients who differed in their therapeutic regimen to control the disease.

The inhalation of hypertonic saline at increasing concentrations up to $5 \%$ can cause bronchial obstruction, especially in patients with a low baseline forced expiratory volume in one second (FEV1) [11]. As the magnitude of obstruction is likely to be related to the duration of inhalation and the concentration of saline, the protocol which included three increasing saline concentrations [8] was modified to a protocol which included only $3 \%$ saline and a $30 \mathrm{~min}$ interval between inhalations to allow for recovery of lung function. To ensure comparability with literature data, the study otherwise adhered to previously validated procedures $[1,7]$.

\section{Methods}

Study design

Each subject completed either a 1- or a 2-day protocol. Methacholine challenges or bronchodilation tests and 
allergen skin tests were performed on the first visit and sputum induction was performed on a second visit (at least $48 \mathrm{~h}$ later). Subjects refrained from their bronchodilator use for $\geq 6 \mathrm{~h}$ before the tests. Subjects from the authors' outpatient clinic were characterized by available medical records and visited the laboratory only for sputum induction. Subjects inhaled nebulized 3\% hypertonic saline for 5 or $10 \mathrm{~min}$ (1st induction) and tried to produce sputum after $5 \mathrm{~min}$ or $10 \mathrm{~min}$, respectively. After $30 \mathrm{~min}$, inhalation was repeated for up to $10 \mathrm{~min}$ (2nd induction), again using 3\% saline.

\section{Subjects}

Detailed anthropometric and clinical data for all subjects are given in table 1. Eleven healthy subjects were included in the study, who were lifelong nonsmokers except for three subjects, who were exsmokers with a smoking history of $<1$ pack-yr and who had stopped smoking $>1 \mathrm{yr}$ before the study. Four subjects showed a positive skinprick test reaction to at least one of 20 common allergens without any symptoms of allergic rhinitis in their medical history. All subjects had been free from acute respiratory tract infections during the 4 weeks before the tests.

Ten patients with COPD were included in the study. Diagnoses were based on to the European Respiratory Society (ERS) Consensus Statement on optimal assessment and management of COPD [12]. All patients with COPD showed a bronchodilator response of $<12 \%$ change in FEV1 10 min after inhalation of $200 \mu \mathrm{g}$ of salbutamol or $200 \mu \mathrm{g}$ of ipratropium bromide. Six COPD patients were treated with oral steroids (mean (range) dose of 10.4 (5-20) mg prednisolone). No patient with COPD had had a recent acute exacerbation, defined as a change in quality and quantity of sputum with increased dyspnoea.

The diagnosis of asthma was assessed according to international guidelines [13]. All patients were nonsmokers. A smoking history of $>10$ pack-yrs and a respiratory tract infection within the last 4 weeks were exclusion criteria. All asthmatic patients showed a provocative concentration causing a 20\% fall in FEV1 (PC20) FEV1 $<8 \mathrm{mg} \cdot \mathrm{mL}^{-1}$ methacholine or, alternatively, a reversibility $(\triangle \mathrm{FEV} 1)$ of $>12 \%$ after inhalation of $200 \mu \mathrm{g}$ salbutamol.
Asthma group 1 included 11 patients with mild asthma who were controlled with $\beta_{2}$-agonists alone, with a mean FEV1 of $90 \%$ predicted. In asthma group 2, 12 patients with mild to moderate asthma were included who were treated with inhaled corticosteroids (mean (range) dose $678(400-1200) \mu \mathrm{g})$ to maintain asthma control. Lung function data in group 2 were similar to those of group 1 . Asthma group 3 included 7 patients with moderate to severe asthma who were treated with inhaled corticosteroids (mean (range) dose $930(500-1200) \mu \mathrm{g}$ ) and additionally with oral corticosteroids (mean (range) dose 14 (5-25) $\mathrm{mg}$ ). In 3 patients, in whom methacholine challenges were not performed, reversibility of airway obstruction was assessed by bronchodilator response as described before (mean increase of FEV1, 57.3\%).

The study was approved by the Ethics Committee of the Chamber of Physicians of the State of Schleswig-Holstein and all subjects gave written informed consent.

\section{Sputum induction}

Before sputum induction, subjects inhaled $200 \mu \mathrm{g}$ salbutamol from a metered dose inhaler. Lung function was measured before and after each inhalation of hypertonic saline using a screen pneumotachograph (Masterscope Version 4.12; Jaeger, Höchberg, Germany) that met published standards [14]. Subjects inhaled 3\% hypertonic saline for up to $10 \mathrm{~min}$ (1st induction) from an ultrasonic nebulizer (NE-U12; Omron, Tokyo, Japan; nominal output $3 \mathrm{~mL} \cdot \mathrm{min}^{-1}$, mean \pm SD delivered amount $1.72 \pm 0.2$ $\mathrm{mL} \cdot \mathrm{min}^{-1}$, mass median diameter $4.9 \mu \mathrm{m}$ ) and tried to produce sputum after 5 and $10 \mathrm{~min}$, respectively. After 30 min, inhalation and sputum induction were repeated for up to $10 \mathrm{~min}$ (2nd induction), again using 3\% saline. Before producing sputum, subjects were asked to rinse their mouth thoroughly, blow their nose, swallow water, and then expectorate the sputum into a plastic petri dish. Sputum samples were processed immediately.

\section{Sputum processing}

Using an inverted microscope adequate plugs of sputum were selected and removed in order to reduce contamination with saliva [7]. Plugs were defined as the more dense

Table 1. - Demographic and clinical data for the different groups

\begin{tabular}{|c|c|c|c|c|c|c|c|c|c|c|c|}
\hline Group & $\mathrm{n}$ & $\begin{array}{l}\text { Sex } \\
\mathrm{M} / \mathrm{F}\end{array}$ & $\begin{array}{l}\text { Height } \\
\mathrm{cm}\end{array}$ & $\begin{array}{l}\text { Age } \\
\text { yrs }\end{array}$ & $\begin{array}{l}\text { Exsmokers } \\
\text { (since yrs) } n\end{array}$ & $\underset{n}{\text { Allergy* }}$ & $\begin{array}{c}\mathrm{PC} 20 \\
\mathrm{mg} \cdot \mathrm{mL}^{-1}\end{array}$ & $\begin{array}{c}\mathrm{VC} \\
\% \text { pred }\end{array}$ & $\begin{array}{l}\text { FEV1 } \\
\% \text { pred }\end{array}$ & $\begin{array}{l}\text { FEV1/ } \\
\text { FVC } \%\end{array}$ & Treatment \\
\hline ont & 1 & & & 2 & & & & & & & \\
\hline $\mathrm{OP}$ & 10 & $9 / 1$ & & 6 & 11 & & $\begin{array}{c}\Delta \mathrm{FEV} 1 \\
3.81 \pm 4.5^{\dagger}\end{array}$ & .6 & & & $\begin{array}{l}\mathrm{OS}=6, \mathrm{~A}=7, \\
\beta_{2}=10, \mathrm{~T}=5\end{array}$ \\
\hline Asthma & & & & & & & & & & & \\
\hline Group 1 & 11 & $7 / 4$ & $6 \pm 8$ & $3.1 \pm$ & $5 /$ & 9 & $0.61^{\dagger}$ & 101 & 89 & & \multirow{3}{*}{$\begin{array}{l}\beta_{2}=11, A=3 \\
\beta_{2}=12, A=2, \\
I S=12 \\
\beta_{2}=6, A=1, \\
I S=7, O S=7\end{array}$} \\
\hline Group 2 & 12 & $9 / 3$ & 177 & 18 & $6 /$ & $11 / 1$ & $59^{*} \pm 6.1^{*}$ & 96 & 5.5 & 73 & \\
\hline Group 3 & 7 & $4 / 3$ & $166 \pm 6.6$ & $58.6 \pm 11.3$ & $3 / 4(18.0)$ & $2 / 5$ & $1.08^{*} \pm 1.7^{*}$ & $79.5 \pm 13.0$ & $50.5 \pm 10.2$ & $50.1 \pm 8.5$ & \\
\hline
\end{tabular}

Data are expressed as mean \pm SD. M: male; F: female; PC20: provocative dose causing a $20 \%$ fall in forced expiratory volume in one second (FEV1); VC: vital capacity; COPD: chronic obstructive pulmonary disease; $\triangle \mathrm{FEV}$ 1: change in FEV1; OS: oral steroids; A: anticholenergic drugs as needed; $\beta_{2}$ : $\beta_{2}$-agonists as needed; T: theophylline; IS: inhaled steriods; numbers indicate the number of subjects with the respective medication. *: skin prick test with a least one positive reaction against 20 common allergens (tests done only in 4 patients for COPD group); $* *$ : mean \pm SD amount of pack-yrs $45.2 \pm 18.9$ for COPD group; ${ }^{\dagger}:$ increase in FEV1 measured before versus 10 min after inhalation of $200 \mu \mathrm{g}$ salbutamol or $200 \mu \mathrm{g}$ ipratropium; ${ }^{\star}$ : geometric mean $\pm \mathrm{SD}$ expressed as a factor. 
and viscid parts and considered to be adequate when the origin from the lower respiratory tract was assured by the presence of nonsquamous cells and low or absent squamous cell contamination. The weight of the selected samples was determined and twice their volume of 6.5 $\mathrm{mM}$ dithiothreitol (sputolysin; Calbiochem, Bad Soden, Germany) was added. After incubation at $37^{\circ} \mathrm{C}$ for $15 \mathrm{~min}$ and repeated mixing of the samples during incubation, phosphate buffered saline (PBS) was added to achieve a 20 -fold final dilution. The samples were centrifuged at $600 \times g$ for $15 \mathrm{~min}$; supernatants were collected and stored at $-70^{\circ} \mathrm{C}$. Cells were resuspended in $1 \% \mathrm{PBS} / \mathrm{bov}-$ ine serum albumin (BSA), and cell counts were performed in a haemocytometer. Cell viability was determined by trypan blue exclusion test, and 10,000-40,000 cells were used to prepare cytospins $(76 \times g, 5 \mathrm{~min})$ and stained with Giemsa. Four hundred nonsquamous cells were counted by two independent investigators and averaged. Cell differential counts were expressed as percentage of nonsquamous cells.

The concentration of eosinophilic cationic protein (ECP) was analysed by the Pharmacia CAP system (Pharmacia \& Upjohn, Erlangen, Germany) and interleukin (IL)-8 was analyzed by enzyme-linked immunosorbent assay (ELISA) (PeliKine Compact® Human Cytokine kits; CLB, Amsterdam, the Netherlands).

\section{Statistical analysis}

For lung function parameters and percentages of cell numbers, arithmetic mean values were computed, for cell numbers per millilitre sputum and fluid phase concentrations of ECP and IL-8 geometric mean values and geometric SEM (expressed as a factor) values were calculated. Statistical comparisons between the first and second spu- tum induction were performed by the Wilcoxon test or Student's t-test when appropriate. For statistical comparisons, data for total cell counts (TCC) and the fluid phase parameters were logarithmically transformed to meet the requirements of homoskedascicity and normal distribution. A $p$-value of $<0.05$ was considered to be significant.

\section{Results}

\section{Lung function data}

Mean baseline FEV1 values before the first and the second sputum induction for the different groups were: 4.58 and $4.62 \mathrm{~L}$ (control group); 1.75 and $1.70 \mathrm{~L}$ (COPD group); 3.42 and $3.47 \mathrm{~L}$ (asthma group 1); 3.47 and $3.52 \mathrm{~L}$ (group 2); 1.77 and 1.64 L (group 3). Patients with COPD and those of asthma group 3 showed the largest mean decrease $(95 \%$ confidence interval (CI)) in FEV1 from baseline after the first induction (-9.1 (-16.5/-1.9) and -13.0 $(-26.2 / 0.4) \%)$. Corresponding values for the control group were $0.8(-2.0 / 3.2) \%,-1.9(6.0 / 2.1) \%$ for asthma group 1 and $-0.2(-3.2 / 2.8) \%$ for group 2 . In all groups, the decrease in FEV1 after the second induction was not significantly different from the decrease after the first induction, except in asthma group 2, which showed a slightly greater decrease after the second induction.

\section{Cellular composition}

The total number of nonsquamous cells per millilitre decreased between the two inductions in the control group and asthma groups 1 and 2, whereas it increased in the COPD group (table 2). Mean viability ranged $78-91 \%$ and did not differ statistically between the two consecutive sputum inductions or between the different groups of subjects studied.

Table 2. - Geometric mean values (95\% confidence intervals $(\mathrm{Cl}))$ for total cell counts and arithmetic mean values (95\% $\mathrm{Cl})$ for differential cell counts

\begin{tabular}{|c|c|c|c|c|c|}
\hline & \multirow[b]{2}{*}{ Control } & \multirow[b]{2}{*}{ COPD } & \multicolumn{3}{|c|}{ Asthma } \\
\hline & & & Group 1 & Group 2 & Group 3 \\
\hline \multicolumn{6}{|c|}{ Total cell counts $\times 10^{6}$ cells $\cdot \mathrm{mL}^{-1}$} \\
\hline First induction & $7.1(3.5-14.4)$ & $8.2(4.4-15.5)$ & $5.2(2.6-10.4)$ & $5.5(3.3-9.2)$ & $5.4(2.0-14.4)$ \\
\hline Second induction & $2.1(1.2-3.9)^{*}$ & $18.5(8.3-40.9)^{*}$ & $2.5(1.2-5.6)^{*}$ & $3.5(2.0-6.1)$ & $7.1(3.2-15.4)$ \\
\hline \multicolumn{6}{|l|}{ Macrophages \% } \\
\hline First induction & $49.3(36.4-62.2)$ & $38.9(21.9-55.9)$ & $55.7(39.5-71.8)$ & $44.8(27.6-61.9)$ & $23.6(11.2-35.9)$ \\
\hline Second induction & $81.1(71.5-90.7)^{* *}$ & $38.1(20.5-55.8)$ & $60.9(44.1-77.6)$ & $55.8(43.3-68.2)$ & $29.7(9.1-50.3)$ \\
\hline \multicolumn{6}{|c|}{ 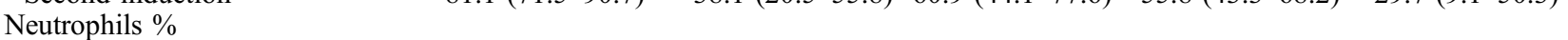 } \\
\hline First induction & $46.1(32.8-59.4)$ & $57.7(39.9-75.5)$ & $20.7(10.6-30.8)$ & $39.7(22.8-56.6)$ & $40.3(10.5-70.2)$ \\
\hline Second induction & $14.5(5.1-24.0)^{* *}$ & $59.2(40.7-77.8)$ & $14.9(9.7-20.1)$ & $26.1(13.2-38.9)^{*}$ & $39.1(6.0-72.2)$ \\
\hline \multicolumn{6}{|l|}{ Eosinophils \% } \\
\hline First induction & $0.7(-0.1-1.5)$ & $1.5(0.4-2.5)$ & $21.2(7.0-35.4)$ & $12.9(-0.2-26.0)$ & $34.2(-1.2-69.6)$ \\
\hline Second induction & $0.3(-0.1-0.7) *$ & $0.9(0.2-1.8)$ & $19.9(3.1-36.8)$ & $11.8(2.8-20.9)$ & $29.5(-3.9-63.0)$ \\
\hline \multicolumn{6}{|l|}{ Lymphocytes \% } \\
\hline First induction & $1.7(1.1-2.2)$ & $1.2(0.4-2.0)$ & $1.6(0.9-2.2)$ & $1.5(1.1-2.0)$ & $1.3(0.4-2.3)$ \\
\hline Second induction & $1.7(0.8-2.7)$ & $1.3(0.03-2.5)$ & $1.5(0.9-2.1)$ & $1.5(0.9-2.1)$ & $1.1(0.6-1.7)$ \\
\hline \multicolumn{6}{|l|}{ Epithelial cells \% } \\
\hline First induction & $1.9(1.0-4.7)$ & $0.6(0.1-1.1)$ & $0.7(0.1-1.3)$ & $1.2(0.5-1.9)$ & $0.6(0.1-1.0)$ \\
\hline Second induction & $2.7(0.05-5.4)$ & $0.4(0.1-0.9)$ & $2.8(-2.1-7.7)$ & $4.8(-3.1-12.7)$ & $0.3(0.01-0.6)$ \\
\hline \multicolumn{6}{|l|}{ Squamous cells \% } \\
\hline First induction & $4.5(0.7-8.3)$ & $2.6(1.0-4.3)$ & $1.9(0.7-3.2)$ & $3.8(1.3-6.3)$ & $2.6(0.3-4.8)$ \\
\hline Second induction & $9.3(3.2-15.4)^{*}$ & $3.8(1.7-5.9)$ & $8.6(-1.9-19.1)^{*}$ & $5.9(1.4-10.4)$ & $4.0(-2.7-10.6)$ \\
\hline
\end{tabular}

Macrophages, neutrophils, eosinophils, lymphocytes and epithelial cells are expressed as percentage of nonsquamous cells. Squamous cells are expressed as percentage of all cells. COPD: chronic obstructive pulmonary disease. *: $p<0.05 ; * *$ : p $<0.01$ between 1 st and 2 nd induction. 
Geometric mean values $(95 \% \mathrm{CI})$ for total cell counts and arithmetic mean values $(95 \% \mathrm{CI})$ for cell differentiation are given in table 2 . In the control group and asthma group 2, percentages of neutrophils decreased and percentages of macrophages increased significantly between the first and second induction. A trend for decreasing percentages of neutrophils was also found in asthma group 1 . In the COPD group and asthma group 3, percentages of neutrophils did not change over the two inductions.

Percentages of eosinophils did not change significantly between the two sputum inductions in the COPD group or any asthma group.

\section{Concentrations of eosinophilic cationic protein and inter- leukin-8}

Concentrations of IL-8 decreased significantly between the two sputum inductions only in the control group and asthma groups 1 and 2 but not in asthma group 3 and the COPD group (table 3). Concentrations of ECP decreased significantly in all groups, with the exception of asthma group 3 .

\section{Discussion}

In this study it was found that two samples of induced sputum collected sequentially within $30 \mathrm{~min}$ differed in their cellular composition. These differences were most pronounced in healthy subjects, in accordance with previous data from the authors' group [8], and became smaller or disappeared in patients with COPD or severe asthma.

For safety reasons, only two instead of the previously used three inhalation periods were used. Despite this, in healthy subjects the decrease in neutrophil numbers from the first to the second sample was similar to that observed between the first and the third sample in a previous study [8]. This finding demonstrates that the modified inhalation procedure was still suitable to detect changes in cellular composition during sequential inductions. However, the modified procedure enabled the investigation of changes in sputum composition in patients with COPD and more severe asthma than studied previously. Differences in the duration of induction are not likely to account for the observed differences in cellular composition since the mean induction times did not differ significantly between the first and second induction for any group.

The percentages of sputum neutrophils in patients with COPD or severe asthma did not change over consecutive sputum samples obtained $30 \mathrm{~min}$ apart, in contrast to healthy subjects. This leads to the speculation that the grad- ient of neutrophils along the airways as observable in sputum is flattened through intermittent spontaneous sputum production by coughing or an impairment in tracheobronchial clearance, thus leading to a similar cellular pattern within consecutive samples.

Patients with bronchial asthma were stratified according to their therapy requirements. Particularly in the second induction, neutrophil numbers increased with increasing severity of the disease, in accordance with data from bronchoalveolar lavage fluid obtained by WeNZEL et al. [15]. In contrast to neutrophils, the percentages of eosinophils did not differ significantly between the two consecutive inductions which is also in accordance with a previous study [8]. This was true for all groups of patients with airway diseases.

It has been suggested that sputum inductions repeated within a time scale of $\sim 40 \mathrm{~min}[8,9]$ initially sample more central airways and finally more peripheral airways. Recent data strongly support this hypothesis as they show a significant increase in surfactant protein A over a sequence of five $4 \mathrm{~min}$ sputum inductions in asthmatic subjects [16]. It is noteworthy that, in contrast to the decrease in the percentage of neutrophils within sputum samples obtained within a short period of time $(30 \mathrm{~min})$, there is an increase in the percentage of neutrophils when sputum inductions are repeated within 8-24 h $[5,6]$, which is likely to represent an inflammatory response to the process of sputum induction by hypertonic saline.

In accordance with previous findings [8], healthy subjects and patients of asthma group 1 and 2 showed a significant decrease in the concentrations of ECP and IL8 between the two consecutive sputum inductions. A possible explanation for this finding is dilution resulting from enhanced water influx after the first induction as caused by the inhalation of the hypertonic saline [17]. In contrast, in patients with more severe asthma (group 3), there was no significant difference between inductions regarding the in patients with concentrations of IL-8 or ECP. Similarly, IL-8 levels did not change COPD.

The data provide further evidence that the duration of sputum induction and the method of pooling might influence the results of cellular composition particularly in healthy subjects and in mild to moderate asthmatics. The data demonstrate that a bias may result when the sputum induction is continued until material of sufficient quality has been obtained. This argument should have implications on the definition of normal values for cell proportions. However, remarkably enough, these effects appear to be less important in patients with more severe asthma or COPD.

Table 3. - Geometric mean values (95\% confidence interval) for concentrations of eosinophilic cationic protein (ECP) and interleukin (IL)-8

\begin{tabular}{lccccc}
\hline & & & \multicolumn{2}{c}{ Asthma } \\
\cline { 4 - 6 } & Control & COPD & Group 1 & Group 2 & Group 3 \\
\hline ECP $\mu \mathrm{g} \cdot \mathrm{L}^{-1}$ & & & & & \\
First induction & $484(225-1040)$ & $1687(649-4388)$ & $2056(717-5897)$ & $1062(410-2750)$ & $1645(514-5259)$ \\
Second induction & $106(44-256)^{* *}$ & $883(385-2024)^{*}$ & $685(181-2586)^{* *}$ & $433(179-1049)^{*}$ & $1385(211-9082)$ \\
IL-8 $\mathrm{ng} \cdot \mathrm{mL}^{-1}$ & & & & & \\
$\quad$ First induction & $17.6(10.6-29.1)$ & $23.4(14.9-36.9)$ & $13.3(7.3-24.0)$ & $13.0(8.2-20.6)$ & $8.9(4.9-16.4)$ \\
Second induction & $7.0(4.1-11.9)^{* *}$ & $17.8(11.0-28.7)$ & $4.9(2.7-9.0)^{* *}$ & $5.6(3.3-9.5)^{* *}$ & $7.6(2.4-24.2)$ \\
\hline
\end{tabular}

$*: \mathrm{p}<0.05 ; * * \mathrm{p}<0.01$ between first and second induction. 
Interestingly, in normal subjects and all groups of patients, the fall in FEV1 induced by the second saline inhalation was not significantly different from that elicited by the first inhalation 30 min before. Thus, there was a lack of refractoriness to hypertonic saline-induced bronchoconstriction, in contrast to results from studies reporting a refractory period to hypertonic saline-induced bronchoconstriction at least in some patients with asthma when inhalations are repeated within $60 \mathrm{~min}[18,19]$. There are no previous data on refractoriness in patients with COPD. Currently, the authors do not have an explanation for this discrepancy.

In conclusion, the approach to collect two sputum samples $30 \mathrm{~min}$ apart revealed significant differences in the cellular composition and the concentrations of soluble components between samples, particularly in healthy subjects and patients with mild to moderate asthma, but not with severe asthma or chronic obstructive pulmonary disease. Differences occurred predominantly in neutrophil numbers; the percentages of eosinophils were similar between inductions. Our findings indicate that standardization of sputum induction is relevant. Furthermore, they suggest that the distribution of inflammatory cells along the airways differs between healthy subjects and patients with chronic obstructive pulmonary disease or asthma of different severity.

Acknowledgements. The authors are grateful to Pharmacia \& Upjohn, Germany, for providing eosinophilic cationic protein kits.

\section{References}

1. Pizzichini E, Morris MM, Efthimiadis A, et al. Indices of airway inflammation in induced sputum: reproducibility and validity of cell and fluid phase measurements. $\mathrm{Am} \mathrm{J}$ Respir Crit Care Med 1996; 154: 308-317.

2. In't Veen JCCM, de Gouw HWFM, Smits HH, et al. Repeatability of cellular and soluble markers of inflammation in induced sputum from patients with asthma. Eur Respir J 1996; 9: 2441-2447.

3. Kips JC, Fahy JV, Hargreave FE, Ind PW, in't Veen JCCM. Methods for sputum induction and analysis of induced sputum: a method for assessing airway inflammation in asthma. Eur Respir J 1998; 11: Suppl. 26: 9s-12s.

4. Popov TA, Pizzichini MMM, Pizzichini E, et al. Some technical factors influencing the induction of sputum for cell analysis. Eur Respir J 1995; 8: 559-565.

5. Holz O, Richter K, Jörres RA, Speckin P, Mücke M, Magnussen H. Changes in sputum composition between two inductions performed on consecutive days. Thorax 1998; 53: 83-86.

6. Nightingale JA, Rogers DF, Barnes PJ. Effect of repeated sputum induction on cell counts in normal volunteers. Thorax 1998; 53: 87-90.

7. Pin I, Gibson PG, Kolendowiez R, et al. Use of induced sputum cell counts to investigate airway inflammation in asthma. Thorax 1992; 47: 25-29.

8. Holz O, Jörres RA, Koschyk S, Speckin P, Welker L, Magnussen $\mathrm{H}$. Changes in sputum composition during sputum induction in healthy and asthmatic subjects. Clin Exp Allergy 1998; 28: 284-292.

9. Gershman NH, Liu H, Liu J, Wong HH, Fahy JV. Fractional analysis of sequential sputum samples during sputum induction. Am J Respir Crit Care Med 1997; 155: A819.

10. Kips JC, Peleman RA, Pauwels RA. Methods of examining induced sputum: do differences matter? Eur Respir $J$ 1998; 11: 529-533.

11. Wong HH, Fahy JV. Safety of one method of sputum induction in asthmatic subjects. Am J Respir Crit Care Med 1997; 156: 299-303.

12. Siafakas NM, Vermeire P, Paoletti P, et al. Optimal assessment and management of chronic obstructive pulmonary disease (COPD). Eur Respir J 1995; 8: 1398-1420.

13. Guidelines for the diagnosis and management of asthma. Expert Panel Report, May 1997 NIH Publication No. 974051A.

14. American Thoracic Society: Standardization of spirometry: 1994 update. Am J Respir Crit Care Med 1995; 152: $1107-1136$.

15. Wenzel SE, Szefler SJ, Leung DY, Sloan SI, Rex MD, Martin RJ. Bronchoscopic evaluation of severe asthma. Persistent inflammation associated with high dose glucocorticoids. Am J Respir Crit Care Med 1997; 156: $737-$ 743.

16. Fahy JV, Liu JT. Different lung compartments are sampled at different time points during sputum induction. Am J Respir Crit Care Med 1998; 157: A613.

17. Pizzichini MMM, Popov TA, Efthimiadis A, et al. Spontaneous and induced sputum to measure indices of airway inflammation in asthma. Am J Respir Crit Care Med 1996; 154: 866-869.

18. Hawksworth RJ, O'Hickey SP, Lee TH. The effects of indomethacin on refractory period to hypertonic salineinduced bronchoconstriction. Eur Respir J 1992; 5: 963966.

19. Belcher NG, Rees PJ, Clark TJH, Lee TH. A comparison of the refractory periods induced by hypertonic airway challenge and exercise in bronchial asthma. Am Rev Respir Dis 1987; 135: 822-825. 